\title{
Paasi, Anssi, Eeva-Kaisa Prokkola, Jarkko Saarinen y Kaj Zimmerbauer (eds). 2019. Borderless worlds for whom? Ethics, moralities and mobilities. Londres: Routledge. 238 p.
}

doi: http://dx.doi.org/10.18543/djhr.1797

Las fronteras ¿para quién se construyen? ¿Dónde están? ¿Sirven para algo en este mundo globalizado y frenéticamente móvil? ¿Por qué algunas personas mueren tratando de atravesarlas y otras atraviesan el mundo para irse de vacaciones sin problemas? ¿Cómo se justifica esta desigualdad? El estudio ético y moral de las fronteras y la movilidad humana es hoy más necesario que nunca. Las fronteras se han convertido en mecanismos que están abiertos y cerrados simultáneamente donde el sistema de exclusas se abre o se cierra dependiendo de quien intente atravesarlas ¿Qué explicación subyace a este abrirse o cerrarse? ¿Qué consecuencias de inclusión o exclusión genera? Estas preguntas nos llevan necesariamente al cuestionamiento de los procesos de fronterización, securitización y sus consecuencias en la vida y la política, en el acceso a derechos y los procesos de exclusión. Este libro ofrece un planteamiento ético y moral absolutamente necesario en un mundo donde las fronteras parecen estar más presentes que nunca.

Anssi Paasi, Eeva-Kaisa Prokkola, Jarkko Saarinen y Kaj Zimmerbauer son los editores del libro, académicos reconocidos, con un fuerte recorrido en los estudios de fronteras desde la geografía política. Las investigaciones que aparecen recogidas en este volumen pertenecen en su mayoría a estudios desde ámbitos relacionados con la geografía humana-crítica y el turismo ofreciendo visiones tan actuales como necesarias. La reflexión ética y moral sobre la movilidad humana y las fronteras constituyen el hilo conductor que da forma al argumento y, a su vez, estructura la reflexión. Esta reflexión ética sirve de guía al lector en el recorrido por los diferentes artículos, autores y perspectivas. Además, la selección de materiales teóricos y prácticos refleja el conocimiento que tienen los editores sobre los debates contemporáneos del estudio critico de fronteras y las lagunas en la literatura.

Los artículos seleccionados en este volumen presentan mayoritariamente visiones desde el norte, con una sobre-representación de la Unión Europea y concretamente de casos y análisis, como Gran Bretaña y el mediterráneo. También destacan los análisis desde 
Norteamericana, concretamente de Estados Unidos y sus fronteras con México, pasando de puntillas por algunos aspectos en Asia, y dejando al margen la situación de la movilidad humana en América central y del sur. África también queda como asignatura pendiente, parece ser la gran olvidada de este libro. Las perspectivas que se presentan quedan pues, ciegas y mudas a gran parte del Sur del mundo.

Tras la ilusión que despertó la globalización de los 90 y el auge de un ideal de una movilidad libre, este libro nos re-sitúa en un mundo donde las fronteras están más presentes que nunca. Muerte, exclusión y sufrimiento suceden en paralelo a la explosión del turismo de masas. La facilidad de movimiento en los viajes por placer y vacacionales contrastan con los impedimentos a los que se enfrentan ciertos sectores de la población mundial para moverse. Los mismos espacios muestran paisajes de movilidad opuestos y en disputa, personas atrapada en las mismas islas donde miles de turistas se mueven libremente para unas vacaciones de ensueño. Las fronteras para el turismo son anecdóticas; para otras personas suponen la vida. El hecho de incluir el turismo como parte de los debates críticos sobre sobre la movilidad humana es pertinente, novedoso y absolutamente necesario desde un punto de vista ético. Este libro ofrece una reflexión obligatoria sobre la desigualdad, la discriminación contemporánea en movilidad humana y los discursos que la legitiman.

Concretamente, el libro presenta una compilación de catorce artículos divididos en cuatro partes que abordan, en primer lugar, los debates relacionados con la posibilidad de un mundo sin fronteras (Borders in a Borderless World); en segundo lugar las cuestiones políticas relativas a los procesos de inclusión y exclusión (Politics of Inclusion and Exclusion), la tercera parte cuestiona las movilidades (Contested Mobilities and Encounters) y, por último, la cuarta parte reflexiona sobre las fronteras en la relación a la seguridad (Borders, Security and Politics).

La parte primera del libro presenta un recorrido reflexivo sobre la idea de un mundo sin fronteras. Esta parte pretende responder a la pregunta de qué supondría un mundo con una movilidad libre. Pocos espacios de discusión académica abordan los efectos y las consecuencias de las tesis sin fronteras como apuesta radical y sus implicaciones éticas. Anssi Paasi en «Borderless Worlds and Beyond. Challenging. The state-centric Cartographies», problematiza la teoría del pensamiento económico neoliberal sobre las fronteras de Kenichi Omae. Paasi plantea un contra-discurso que coloca nuevamente en el centro la realidad innegable de que las fronteras siguen siendo factores fundamentales en la configuración geopolítica del mundo. El estudio 
de las migraciones implica, para Paasi, imaginar mundos más allá de las teorías y las prácticas contemporáneas y exige poner encima de la mesa cuestiones morales y éticas sobre la construcción de la justificación del quién, cómo y cuándo se incluye o se excluye. En el segundo artículo, Harald Bauder («lmagining a Borderless World») continúa explorando la posibilidad de un mundo sin fronteras, indicando las hipotéticas dificultades que se generarían. El autor analiza la ambigüedad de los términos de «libertad» y de "frontera», aplicándolo a las teorías de libertad de movimiento. Por último, Paolo Novak en «Borders, Distance and Politics», plantea la posibilidad de que las teorías sobre un mundo sin fronteras hayan sido precisamente eso, sólo teorías relacionadas con el momento histórico y la globalización de los 90. Novak aborda, en primer lugar, la localización de las fronteras, es decir, dónde están, dónde se encuentran, dónde actúan. En segundo lugar, el autor reenmarca el debate en términos epistemológicos sobre el proceso de producción espacial.

La parte segunda plantea cuestiones sobre la inclusión y la exclusión como un proceso dinámico en constante articulación. El bloque nos guía a través de cuatro ejemplos de procesos de inclusión/exclusión en cuatro capítulos. En primer lugar, el Brexit («Borderless Europe and Brexit: Young european migrant accounts of media uses and moralities») sirve como excusa para reflexionar sobre el dinamismo en los procesos de pertenencia, inclusión y en las identidades nacionales e individuales en el seno de la UE. Su autora, Aija Lulle reflexiona sobre las dinámicas emergentes las líneas de desconexión, los medios de comunicación y las fronteras diarias en las migraciones intra-europeas. Kathryn Cassidy en el segundo artículo («Everyday bordering, healthcare and the Politics of Belonging in Contemporary Britain»), usa el sistema público de salud en Gran Bretaña para analizar cómo se ha fronterizado. Las fronteras actúan como barreras en el acceso a los servicios públicos y nos sirven como elemento de reflexión moral sobre quién pertenece y quién queda excluido. En tercer lugar, el análisis surge a partir del estudio del trabajo humanitario en las fronteras. En «Delay and neglected. The everyday Geopolicitcs of Humanitarian Borders», Elisa Pascucci, Jouni Häkli and Kirsi Pauliina Kallio, examinan los procesos de fronterización europea a través de los casos de las islas griegas y el Líbano. El artículo pone el foco en la similitud e interconexión de las prácticas diarias en las fronteras y el humanitarismo como parte de la gobernanza global de las migraciones. Por último, los editores presentan un ejemplo que viene del caso finlandés y de su proyecto de construcción de identidad nacional y su intersección con el género. Eeva-Kaisa 
Prokkola (Asylum and the politization of National Identity in Finland: a gender perspective), plantea cómo el género impregna la propia naturaleza de la frontera. La autora reflexiona sobre construcción de la identidad nacional y sobre cómo la vulnerabilidad de las mujeres ha jugado un papel crucial en la justificación de la securitización de la frontera finlandesa en un contexto de recepción de solicitantes de asilo durante el año 2015. El análisis de las entrevistas muestra cómo la protección/securitización de las fronteras y el orden nacional masculino se hacen visibles sobre todo en lo que respecta a las imágenes de mujeres jóvenes representadas como inocentes y, por tanto, en peligro ante los solicitantes de asilo. Los solicitantes de asilo se convierten así en una amenaza para la nación y para las mujeres jóvenes finlandesas.

La parte tercera, Contested Mobilities and Encounters, consta de tres artículos que enfatizan la movilidad como contrapeso al estudio siempre más abundante de las inmovilidades. Hace falta ir más allá y poner la mirada moral y ética en la movilidad, en el turismo, en el cruce diario de fronteras y en la mercantilización de estos espacios. El primer artículo, de Raoul V. Bianchi y Marcus L. Stephenson («Tourism, Border Politics, and the Fault Lines»), se abordan las asimetrías globales en la movilidad humana, entre el turismo y aquellos condenados a la falta de derecho a atravesar fronteras. El capítulo re-politiza el turismo colocándolo en el centro de las políticas globales de movilidad. Los autores hacen un recorrido crítico-histórico, muy pertinente, sobre el nacimiento y la evolución del turismo como fenómeno relacionado con la democratización, la sociedad de masas y como fenómeno que fomenta la paz y el desarrollo internacional. Plantean una mirada crítica necesaria buscando las relaciones entre turismo y colonialismo como fenómenos que sucedían (y suceden) al mismo tiempo. De la misma manera en la que hoy la restricción de la movilidad sucede a la vez y en contra posición con el turismo de masas. Turismo y contención forman parte de las mismas dinámicas globales. Los autores sugieren que la movilidad internacional es discriminatoria con las poblaciones racializadas, sobre todo con la comunidad musulmana, que se ha convertido en el punto de mira de las políticas securitarias. Los autores sugieren que las tecnologías de control fronterizo y las prácticas de gobernanza de fronteras junto con la securitización de las mismas están intrínsecamente ligadas a la discriminación de las poblaciones radicalizadas. En segundo lugar, Stoffelen y Dominique Vanneste («Commodification of Contested Borderscapes for Tourism, Development, Viability, Community Representation and Equity of Relic Iron Curtain and Sudetnland Heritage Tourism Landscapes») 
analizan los aspectos éticos en el proceso de mercantilización de las fronteras como espacios turísticos a través del ejemplo de la frontera entre Alemania y la República Checa. Se centran en el proceso de mercantilización y cómo este, en ocasiones, da lugar a movilizaciones sociales de protesta. La promoción del turismo en espacios fronterizos puede influir dando forma a los discursos sobre memoria colectiva, políticas y dinámicas fronterizas, convirtiendo espacios hostiles en espacios de atracción turística. Por último, "Contested Mobilities Across the Hong Kong-Shenzhen Border, the Case of Sheung Shui», escrito por J.J Zhang, plantea la necesidad de poner el foco en los cruces de frontera que diariamente realizan millones de personas. El autor analiza las dinámicas de cruce entre un pueblo del sur de China y la ciudad de Sheung Shui en Hong Kong. Concretamente estudia preliminarmente las políticas y prácticas de consumo y de contestación transfronterizo. Las fronteras no se han evaporado, las fronteras crean nuevos espacios de encuentro y conflicto, de movilidad y de inmovilidad. Las consideraciones éticas y morales son necesarias en el estudio de la movilidad.

La última sección del libro, Border, Security, Politics, consta de cuatro artículos, todos referentes al norte del mundo, concretamente a Norte América y Europa, y de un epílogo. Este bloque quizás sea el más heterogéneo. Presenta las interacciones y resultados posibles entre fronterización, política, poder, acción de los estados, prácticas y sociedad civil. Heather N. Nicol y Karen G. Everett, escriben «Trade, Trump, Security and Ethics, the Canadian-US Perspective». El artículo mapea la región y analiza cómo el mismo país, en este caso Estado Unidos de América, construye frontera de manera diferente con Canadá y con México. Esta diferenciación tiene implicaciones morales. Los autores presentan un escenario de gestión diferenciada donde los acuerdos mercantiles entran a formar parte de las negociaciones con respecto a la gestión migratoria. En «Ontological (In)Securitty. The EU's Bordering Dilema and Neighbourhood», Jussie Laine y James Scott exploran la política europea de vecindad reflexionando sobre la construcción del propio concepto de vecindad, los imaginarios que se generar en torno a él y el propósito de su orientación política. Hacen una crítica post-colonial, hablando de reduccionismo neo-colonial que simplifica las regiones y las convierte en un mismo espacio de «vecinos». Asimismo, reflexionan sobre la autopercepción de la UE como promotora de valores universales y modos de vida ejemplares, objeto de réplica para sus vecinos. Los imaginarios de cooperación y comunicación que van implícitos en la política de vecindad reflejan una idea de no-conflicto, de necesidad de adaptación a valores y morales 
europeos que generarían naturalmente aliados políticos. El artículo plantea la pregunta de cómo los imaginarios alimentan la seguridad ontológica europea y su identidad. El tercer artículo de Elisabetta Nadalutti («Ethical Code for Cross-Border Governance, What does the European Union Say on Ethics of Cross Border Cooperation?») analiza las políticas europeas de cooperación transfronteriza. La autora se centra en la dimensión ética de la gobernanza de fronteras apoyándose en un trabajo cualitativo cobre los planes de cohesión territorial de la UE. La burocracia de la cooperación transfronteriza esta sistematizada pero no sucede lo mismo con las cuestiones éticas. Concretamente la autora estudia la región del adriático y sugiere que debería operacionalizarse una ética de cooperación transfronteriza de manera oficial.

Por último, el artículo de Estela Shindel («The Role of Nature at the EU Maritime Borders, Agency, Ethics and Eccountability») resulta especialmente relevante. Estela, tras hacer un recorrido por autores que han trabajado el concepto de «naturaleza» con respecto a «lo humano», plantea la necesidad de politizar los elementos «ambientales» (el mar, el sol, las montañas) que aparecen relacionados con las muertes en las fronteras. La politización tiene como objetivo identificar las responsabilidades políticas en lo que sucede dentro de los espacios fronterizos. El aumento de la vigilancia y la securitización en las fronteras ha empujado a las personas migrantes a tomar otras rutas asumiendo cuotas muy elevadas de peligrosidad, dolor y riesgo de muerte. Estas rutas clandestinas exponen a las personas a perder la vida a causa de lo que se presenta como "factores medioambientales». Este artículo reflexiona sobre las cuestiones éticas, la responsabilidad política y la transparencia en los espacios fronterizos. ¿Quién es responsable de generar las condiciones a las que se enfrentan las personas en las fronteras? ¿Es la naturaleza realmente algo externo y ajeno que genera muerte? Es imprescindible reflexionar sobre qué es lo que se entiende como efectos naturales para poder señalar responsabilidades. La muerte y el sufrimiento en las fronteras no es visible, no es fácil de conocer (accountability), se presenta como una realidad opaca, ajena. La clave ética y moral en este artículo es la pregunta: ¿hasta qué punto las cuestiones geográficas y topográficas, meteorológicas y físicas forman parte de los cálculos y de las estrategias en el control de fronteras? Los factores naturales son externos, ajenos, ahistóricos, la falta datos y la inexistencia de criterios estandarizados para obtener información contribuyen a la falta de reflexión crítica sobre las fronteras. Para señalar responsabilidades no solo es necesario politizar lo natural sino también los espacios de acción humanitaria. La 
autora remarca que no habría ningún marco teórico o legal para las practicas que están dejando a las personas migrantes a la merced de los elementos, del mar, del desierto. Las muertes en las fronteras están políticamente inducidas por los regímenes de fronteras.

Daniela Lo Coco Universidad de Deusto 


\section{Copyright}

Deusto Journal of Human Rights / Revista Deusto de Derechos Humanos is an Open Access journal; which means that it is free for full and immediate access, reading, search, download, distribution, and reuse in any medium only for non-commercial purposes and in accordance with any applicable copyright legislation, without prior permission from the copyright holder (University of Deusto) or the author; provided the original work and publication source are properly cited (Issue number, year, pages and DOI if applicable) and any changes to the original are clearly indicated. Any other use of its content in any medium or format, now known or developed in the future, requires prior written permission of the copyright holder.

\section{Derechos de autoría}

Deusto Journal of Human Rights / Revista Deusto de Derechos Humanos es una revista de Acceso Abierto; lo que significa que es de libre acceso en su integridad inmediatamente después de la publicación de cada número. Se permite su lectura, la búsqueda, descarga, distribución y reutilización en cualquier tipo de soporte sólo para fines no comerciales y según lo previsto por la ley; sin la previa autorización de la Editorial (Universidad de Deusto) o la persona autora, siempre que la obra original sea debidamente citada (número, año, páginas y DOI si procede) y cualquier cambio en el original esté claramente indicado. Cualquier otro uso de su contenido en cualquier medio o formato, ahora conocido o desarrollado en el futuro, requiere el permiso previo por escrito de la persona titular de los derechos de autoría. 